\title{
The Link Between Incoterms 2000 and Letter of Credit Documentation Requirement and Payment Risk
}

\author{
Roberto Bergami \\ Victoria University, Australia
}

\begin{abstract}
Letters of credit are an important finance instrument for international trade. These instruments are particularly useful in trade where the transactional values and trading risks are high. Essentially the letter of credit is a substitute for a buyer's risk with that of his bank, as it underwrites the transaction. Exporters experience difficulties in achieving documentary compliance to the bank's satisfaction and therefore run the risk of not being paid. Compliance is based on the accuracy and form of data content on documents required by the letter of credit. The more voluminous and complex the documentary requirements, the higher the non-compliance risk. This paper explores the link between international delivery terms and documentary requirements of the letter of credit. Preliminary data from an industry survey suggests that exporters are contracting on international delivery terms that may leave them unnecessarily exposed to non-payment risks. Although further investigation is required to determine whether alternate delivery terms would diminish the exporter's risk, preliminary results indicate that it is possible to reduce payment risk by the strategic use of international delivery terms.
\end{abstract}

\section{Introduction}

Letters of Credit (L/C) are considered to be one the most important financial instrument in international trade transactions, having been described as the "life blood of international commerce" (D'Arcy, Murray and Cleave 2000). The actual amount of L/C transactions has proved difficult to quantify. Estimates from personal interviews with senior banking personnel in Thailand and Malaysia have indicated that $\mathrm{L} / \mathrm{C}$ transactions account for nearly half of their international trade transactions. Anecdotal evidence in Australia seems to support these statements. Raw data for Australia's L/C trade does not appear to be publicly available. The lack of data is probably due to the fact that the Australian banking industry has an oligopolistic structure and there is no evidence that data on international trade transaction details is publicly released. In attempt to gather some information about this aspect of banking, enquiries were made to the major banks in Australia, the Reserve Bank of Australia and SWIFT (the banking system electronic international communication and clearing house, but the release of information was declined, even at the macro level. However, overseas data for the US suggests annual commercial L/C business turnover of approximately USD 51,648 millions in 2003 (Documentary Credit World 2003). The total value of US trade for the same period is estimated at USD 1,922,724 millions (United States International Trade Commission 2004). The commercial L/C

Copyright (C) 2006 Victoria University. This document has been published as part of the Journal of Business Systems, Governance and Ethics in both online and print formats. Educational and non-profit institutions are granted a nonexclusive licence to utilise this document in whole or in part for personal or classroom use without fee, provided that correct attribution and citation are made and this copyright statement is reproduced. Any other usage is prohibited without the express permission of the business therefore accounts for approximately 4 percent of trade. These figures indicate that, as an international finance tool, $\mathrm{L} / \mathrm{C}$ are significant and widely used, accounting for billions of dollars in annual trade. As the L/C business is largely international, it may be presumed that similar usage proportions apply to the Australian situation.

L/Cs tvpically work through the banking 
system and are subject to the Uniform Customs and Practice for Documentary Credits (UCP 500) rules devised by the International Chamber of Commerce (ICC). These rules were issued in 1993 and are currently under review. For the exporter, the $\mathrm{L} / \mathrm{C}$ substitutes the credit risk of the buyer with that of his bank. The L/C is a conditional 'payment guarantee' (AusIndustry 1996, p. 18). The Issuing Bank (buyer's bank) undertakes to "buy" specified documents (representing the existence of the goods) from the beneficiary (exporter), provided they comply $100 \%$ with the $\mathrm{L} / \mathrm{C}$ requirements, otherwise the 'payment guarantee' is lost. Non-compliance is a significant problem as, according to the ICC, worldwide documentary discrepancy rates against L/Cs are between $60 \%$ to $70 \%$ (ICC Thailand 2002). The mechanics of $\mathrm{L} / \mathrm{C}$ transactions give rise to a complex web of interactions between banks, traders and service providers alike providing a fertile ground for discrepancies.

\section{The Contractual Arrangements of L/C Transactions}

The decision to use the $\mathrm{L} / \mathrm{C}$ as a payment method gives rise to a number of separate contracts, as shown in Figure 1.

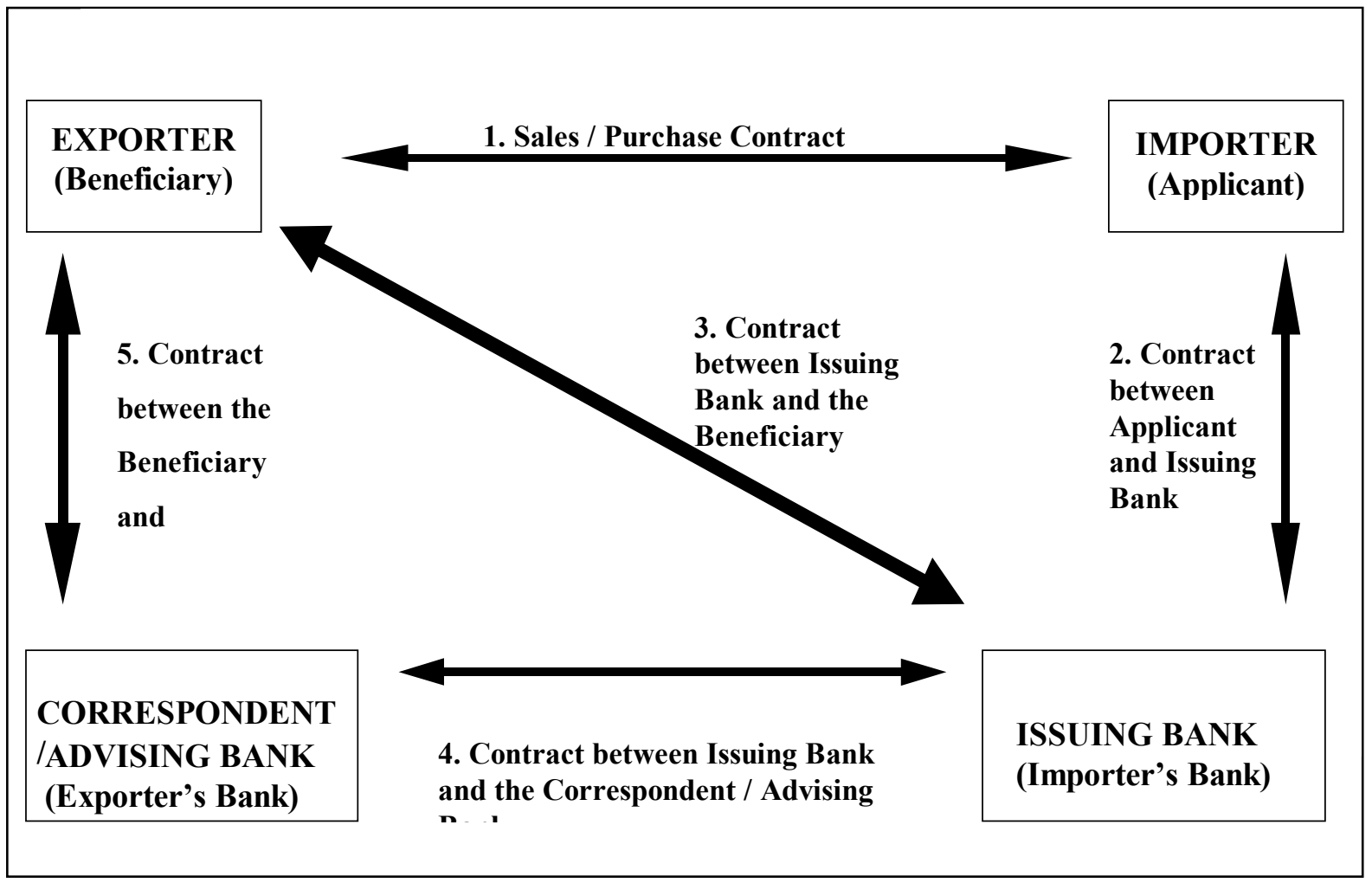

Figure 4: Typical contracts of a letter of credit transaction (Bergami 2006, p. 415)

Contract number 3 in Figure 1 is the crucial link between the payment guarantee and the banking requirements. It can be observed that, in so far as payment is concerned, there are no other direct links between the seller and the buyer, other than the contract of sale. This situation reflects the independence principle that operates in L/C transactions, as per UCP 500 article 3 that states in part:

... credits, by their nature are separate transactions from the sales or other contract(s) on which they may be based and banks are in no way concerned with or bound by such contract(s), even if any reference whatsoever is included in the credit (International Chamber of Commerce 1993).

However the banking requirements that trigger the payment under a $\mathrm{L} / \mathrm{C}$ transaction depend on documentation, as per UCP 500 article 4 that states: In credit operations all parties concerned deal with documents, and not with goods, services and/or other performances to which the documents may relate (International Chamber of Commerce 1993). 
The question of documentation and its required data contents therefore becomes a central issue in considering the risks involved in an $\mathrm{L} / \mathrm{C}$ transaction. In essence the exporter must present documents that are L/C compliant to assure payment. Whilst the UCP 500 separates contract from payment, the documentary requirements are influenced by business practices between the parties that lead to the contract formation in the first instance. The contract of sale is the starting point for all subsequent action, as shown in Figure 1, Contract number 1. Therefore it is necessary to delivery terms of a contract, because these terms determine the documentation requirements that are subsequently incorporated into the $\mathrm{L} / \mathrm{C}$.

\section{Incoterms 2000: International Delivery Terms}

One of the fundamental considerations in any international contract for the sale of goods is the delivery of the cargo to an agreed place, and this is where the Incoterms play a vital role. Devised by the ICC, Incoterms are an acronym for International Commercial Terms. Issued for the first time in 1936, they have been regularly updated with the current version being the Incoterms 2000 . These terms are not an international convention, and therefore their incorporation into international contracts is voluntary. Incoterms 2000 have been readily accepted by the trading world for over a decade, probably since the United Nation's Commission on International Trade Law that, on 12 May 1992, officially endorsed ICC Incoterms 1990 and commended their use in international sales transactions (ICC Australian Council 1992).

There are thirteen Incoterms, each different with different rights, duties, obligations and responsibilities on the trading parties. The choice of Incoterms therefore controls the amount of risk exposure each parties has. A number of subsidiary contracts result from the usage of Incoterms and these are shown in Figure 2. The exporter will need to deliver according to the Incoterm chosen, and this will be reflected in the documentary $\mathrm{L} / \mathrm{C}$ requirement.

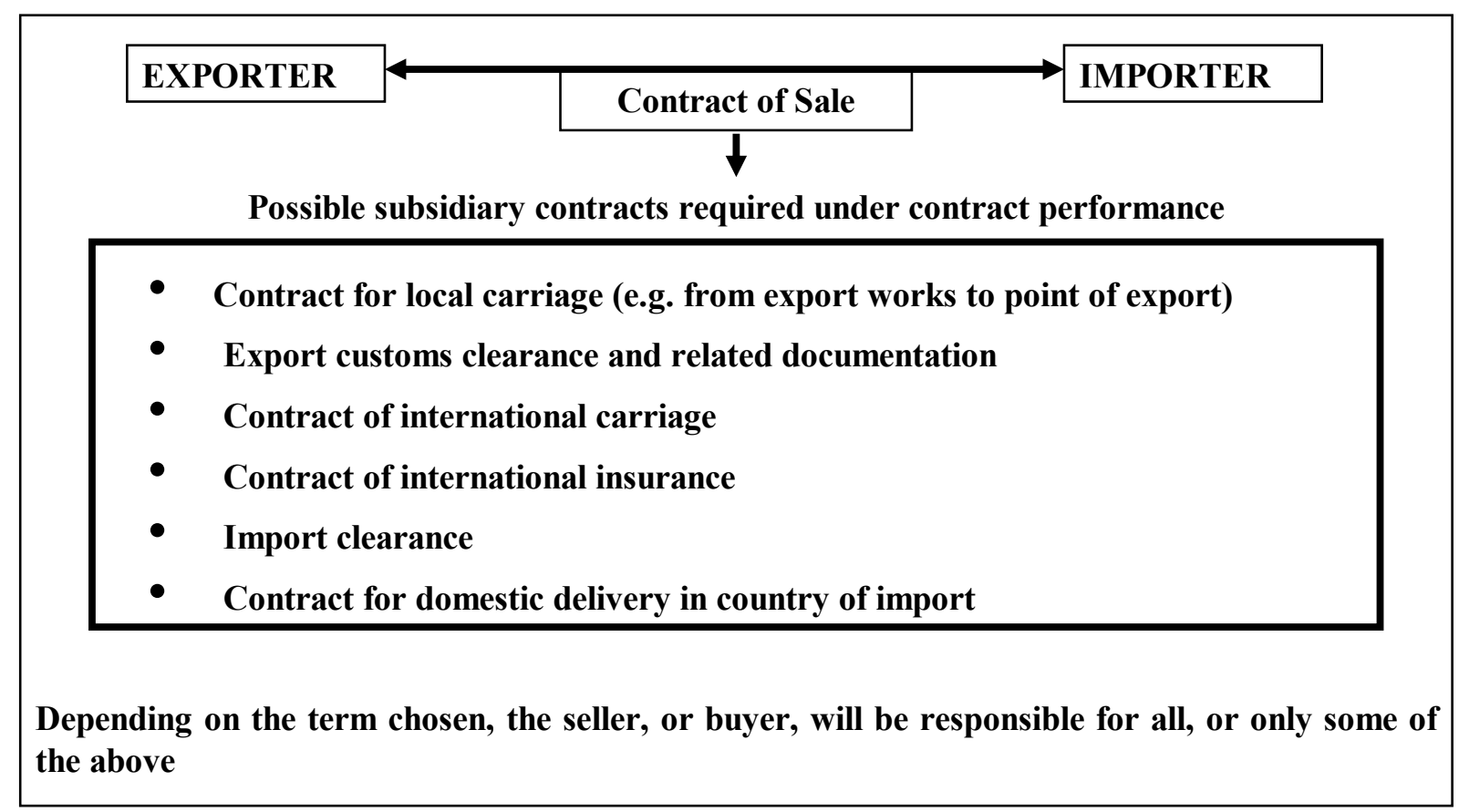

Figure 5: Subsidiary contract (for the movement of goods) arising from the sales contract. (Bergami 2006)

Incoterms apportion the actions to be taken by one party or the other on a mutually exclusive basis, that is to say, if the exporter is responsible for arranging export customs clearance, the importer will not be. It is therefore important to understand the obligation imposed by each term, as this is linked to the provision of documents. The international transaction is complex and typically involves a number of external service providers. Whilst some of the required documentation may be produced in-house by the 
exporter, other documents, such as transport documents, can only be acquired from external sources. Incoterms comprise of four groups and each of these is detailed below.

\section{Group E: EX -Works (EXW)}

There is only one terms in this group, requiring the least effort from the exporter. Basically the exporter only has to pack, mark and label the goods in accordance with the contractual requirements and make the cargo available at the agreed works (place of cargo collection). There is no obligation for the exporter to load the goods on the collecting vehicle, become engaged in customs clearance formalities for export or import, or be a party to any of the contracts of carriage or insurance (International Chamber of Commerce 1999). Consequently the documentary requirements under EXW are minimal. The provision of a commercial invoice and at best proof of collection of the goods from the nominated warehouse would be all that is required.

\section{Group F: Free Carrier (FCA); Free Alongside Ship (FAS); Free On Board (FOB)}

With this group, the exporter is responsible for export clearance and the placement of the consignment, at an agreed point in his country (International Chamber of Commerce 1999). The burden of documentation is increased and whilst the exporter is under no obligation to enter into a contract of carriage he must "render the buyer at the latter's request, risk and expense, every assistance in obtaining a transport document for the contract of carriage" (International Chamber of Commerce 1999). The seller's responsibility to render this type of assistance is translated in practice to a letter of credit demand for the transport document to be submitted as part of the documentary requirement, particularly in FCA and FOB transactions.

\section{Group C: Cost and Freight (CFR); Cost, Insurance and Freight (CIF); Carriage Paid to (CPT); Carriage and Insurance Paid To (CIP)}

The exporter's documentation burden is further increased under this group. In all four terms the exporter has an obligation to enter into a contract of carriage and therefore tender the transport document to the buyer (International Chamber of Commerce 1999). In an L/C transaction the transport document will invariably be sought by the bank. For CIF and CIP terms, the exporter is additionally required to enter into a contract of cargo insurance "with underwriters or an insurance company of good repute" (International Chamber of Commerce 1999). The exporter must "provide the buyer with the insurance policy or other evidence of insurance cover" (International Chamber of Commerce 1999). This is to enable the buyer, once the risk in transit has transferred to him, to independently lodge a claim with the insurers as after all, the buyer has paid for this insurance cover through the price charged for the goods (Ramberg 1999). It is important to note that insurance cover notes are not usually accepted by banks, unless specifically allowed for in the L/C under UCP 500 Article 34(c) (International Chamber of Commerce 1993; Technical Officers of Global International Trade \& Business Finance 2000)

\section{Group D: Delivered at Frontier (DAF); Delivered EX Ship (DES); Delivered EX Quay (DEQ); Delivered Duty Unpaid (DDU); Delivered Duty Paid (DDP)}

The exporter's obligations under this group include the responsibility of causing the product to be placed at an agreed delivery point. Because the movement of cargo is undertaken at the exporter's risk, there is no requirement for the buyer to receive proof of insurance and consequently no insurance documents will be provided or called for by banks in a $\mathrm{L} / \mathrm{C}$ transaction. Proof of delivery in this group may need to be provided by a number of different means. This may take the form of a delivery order to the frontier for DAF transactions (International Chamber of Commerce 1999), or a transport document/delivery order that would enable the buyer to claim or collect the goods at the arrival port, or other agreed delivery location.

The type of documentation required is therefore linked to the chosen Incoterm. As discussed in the next section, the sequence of events in establishing the $\mathrm{L} / \mathrm{C}$ influences the documentary requirements. 


\section{The L/C Operations}

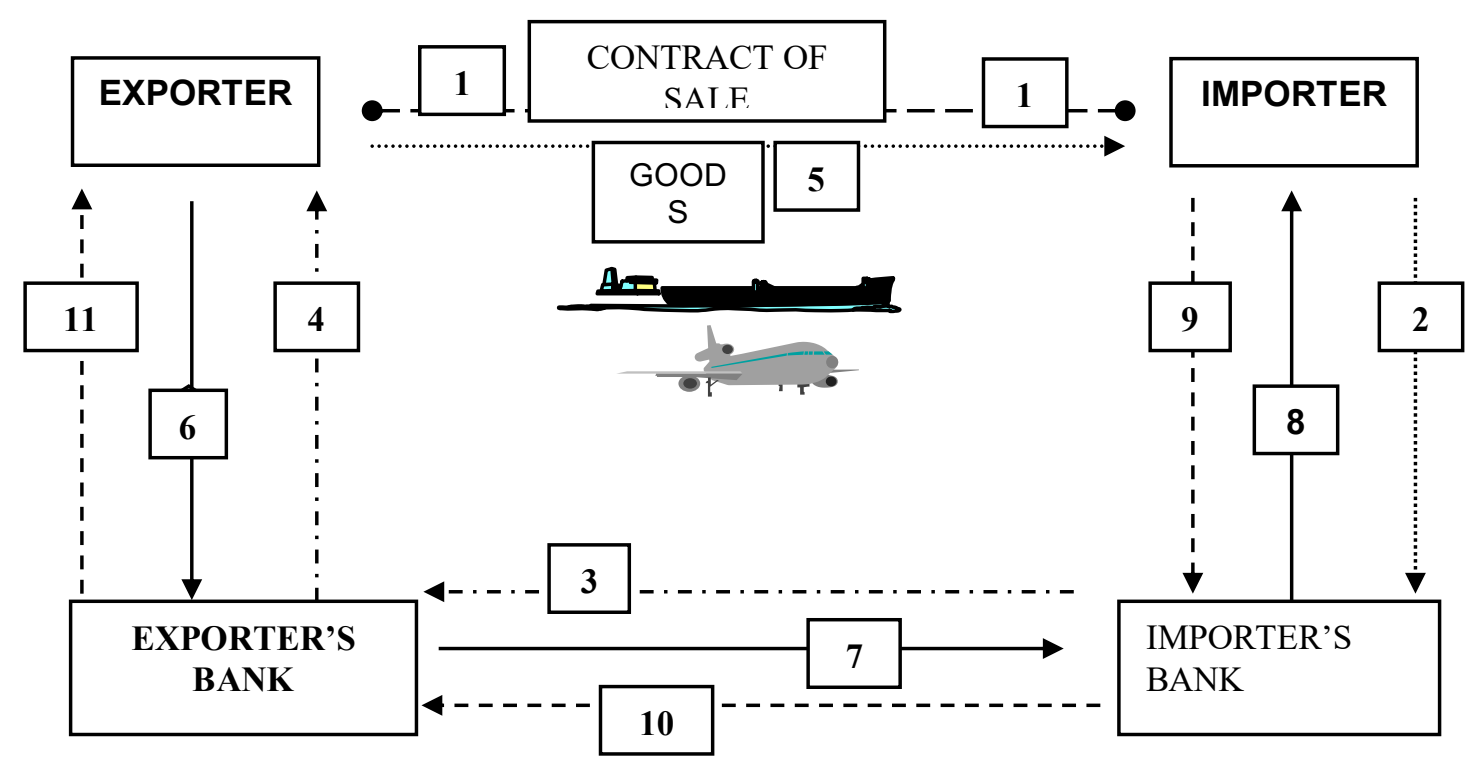

Legend:

1. Contract of sale between the parties $-\mathrm{L} / \mathrm{C}$ is the method of payment chosen

2. Importer lodges $\mathrm{L} / \mathrm{C}$ application with issuing bank

3. Issuing bank issues $\mathrm{L} / \mathrm{C}$ to advising bank

4. $\mathrm{L} / \mathrm{C}$ advised to exporter

5. Goods despatched

6. Required paper based documents lodged by exporter to the bank (altogether in one presentation)

7. Documents sent to issuing bank for acceptance

8. Documents released to importer

9. Funds transferred from importer on due date

10. Funds transferred from issuing bank

11. Funds transferred to exporter

Figure 6: Typical letter of credit transaction cycle (deferred payment option)

Step 2 in Figure 3, is the L/C application by the buyer (importer/applicant). This application outlines the requirements for the transaction and is meant to reflect the spirit of the contract of sale. It is at this stage that the importer indicates to the issuing bank the documentary requirements. Typically this is conveyed through a standard L/C application form, modelled on the Society for Worldwide Interbank Financial Telecommunication (SWIFT) messaging system. SWIFT is the electronic messaging system that banks in developed countries commonly use, as is the case in Australia. The completed application form replicates the data fields to be completed in the SWIFT system. The application is lodged by the buyer and scrutinised by the bank that may, after having conducted the usual commercial assessment of the application, decide to issue the $\mathrm{L} / \mathrm{C}$ to the exporter (seller/beneficiary). The $\mathrm{L} / \mathrm{C}$ is typically advised through the banking system due to security and integrity concerns (step 3). Once the $\mathrm{L} / \mathrm{C}$ has been received and verified as authentic it is forwarded to the exporter (step 4). It is at this stage that the exporter should check that the terms and conditions of the letter of credit match those of the sales contract and that the documentary requirements can be met. Any discrepancies or difficulties should be corrected before the goods are sent. 
Once the cargo has been despatched (step 5) the exporter's task is gather the necessary documentation and present this to the bank (step 6). This is the most critical step in the whole transaction. If the exporter is able to present compliant documents, payment is assured.

\section{Why are Documentary Discrepancies so High?}

Although not highly researched, documentary $\mathrm{L} / \mathrm{C}$ compliance has been a problem for some time in international business, as evidenced by surveys undertaken in 1983/1984 and again in 1989/1991 and in 2003, the ICC figures of 50\% to 60\% discrepancies were confirmed (SITPRO Ltd. 2003, p. 3). In one study in the US, discrepancy rates were reported to be $73 \%$ (Mann 2000, p. 2497). The method employed in assessing the existence of documentary discrepancies in the US study was the systematic examination of data from files held by banks. In the UK the method used for gathering data was by means of a survey of three banks. Discrepancies certainly cost money:

The review estimates that in 2000 the UK lost $£ 113$ million through non-compliant documents being presented under letters of credit. This is merely the amount that can be measured and does not include other factors such as lost opportunity and cash flow problems. This is an enormous amount of money to be taken out of often very narrow margins (SITPRO Ltd. 2003).

The above comments reflect the reality of the situation for exporters in both the US and the UK, but similar problems face Australian exporters. Industry sources in Australia claim that discrepancy rates are in line with estimates by the ICC. To gather data on discrepancy rates in Australia, a random survey of Australian manufacturing exporters to ASEAN was conducted in 2005 and preliminary results from this survey are discussed below. It should be noted that discussion on the complete survey is beyond the scope of this paper, and consequently only the relevant responses are considered here.

\section{Survey of Discrepancy Rates and Incoterms 2000 Usage}

The survey attracted 102 respondents, and they reported the discrepancy rates experienced in L/C export transactions, shown in Figure 4 below.

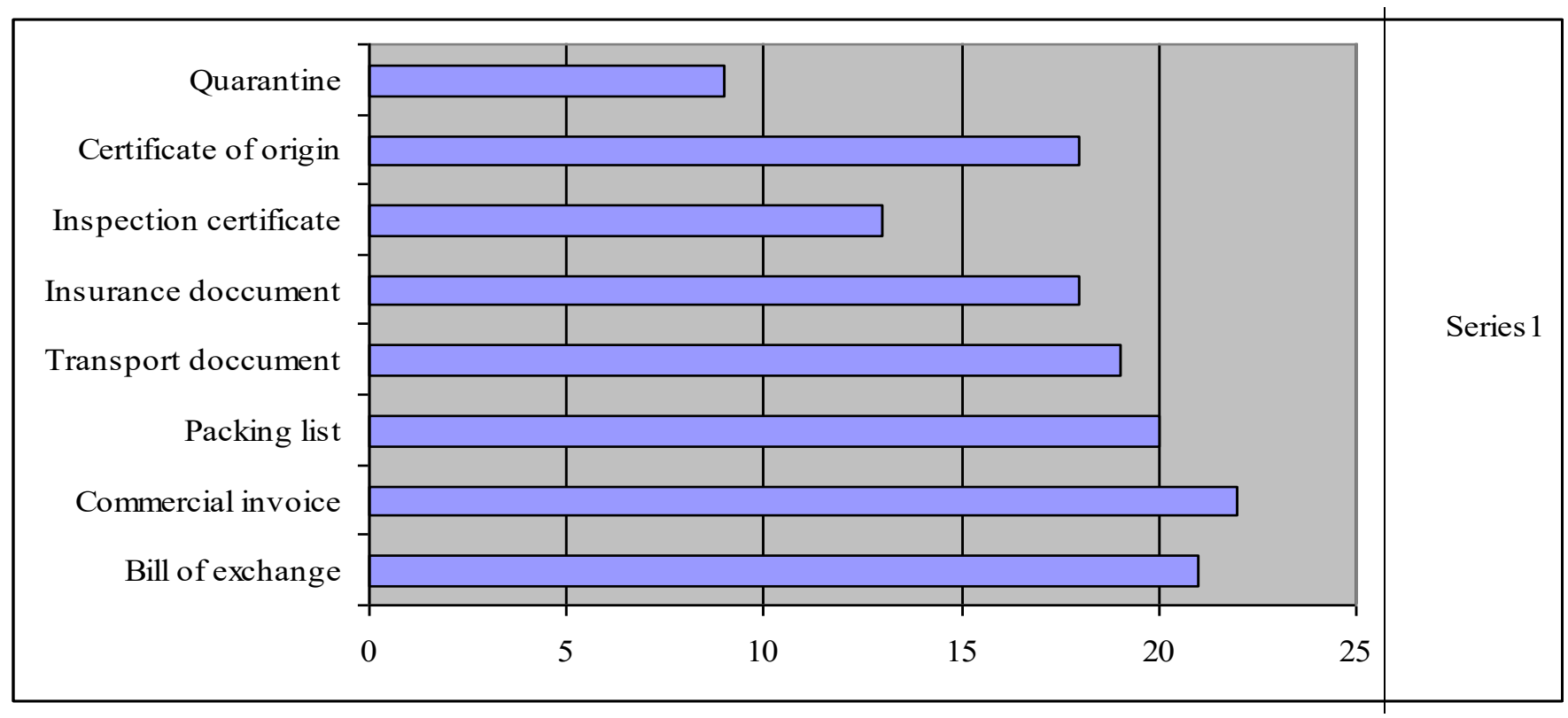

Figure 7: Discrepancy frequency on export letter of credit

From the list provided, only three of the eight documents identified are capable of being produced inhouse by the exporter, these being the Bill of exchange, the Commercial invoice and the Packing list. Arguably the Insurance document could also be produced in-house where an Open Insurance policy 
exists. This type of insurance policy allows the exporter to complete his own insurance declaration and issue certificates of insurance acting as a virtual agent of the insurance company for such purposes. The remaining documents are produced externally, without exception, although the instructions for the completion of such documents may actually originate with the exporter. For example the transport document and certificate of origin is usually completed based on information provided from the exporter to the transport provider or certification authority prior to the carriage of the goods.

Having identified the discrepancy areas in the documentation, the usage of Incoterms also needs to be considered to determine whether there are any links between the choice of Incoterms and the resultant mandatory provision of documentation that form part of the $\mathrm{L} / \mathrm{C}$ transaction.

\section{The Incoterms 2000 Usage and Patterns}

Figure 5 shows the preferred usage of Incoterms among the surveyed Australian manufacturing export base.

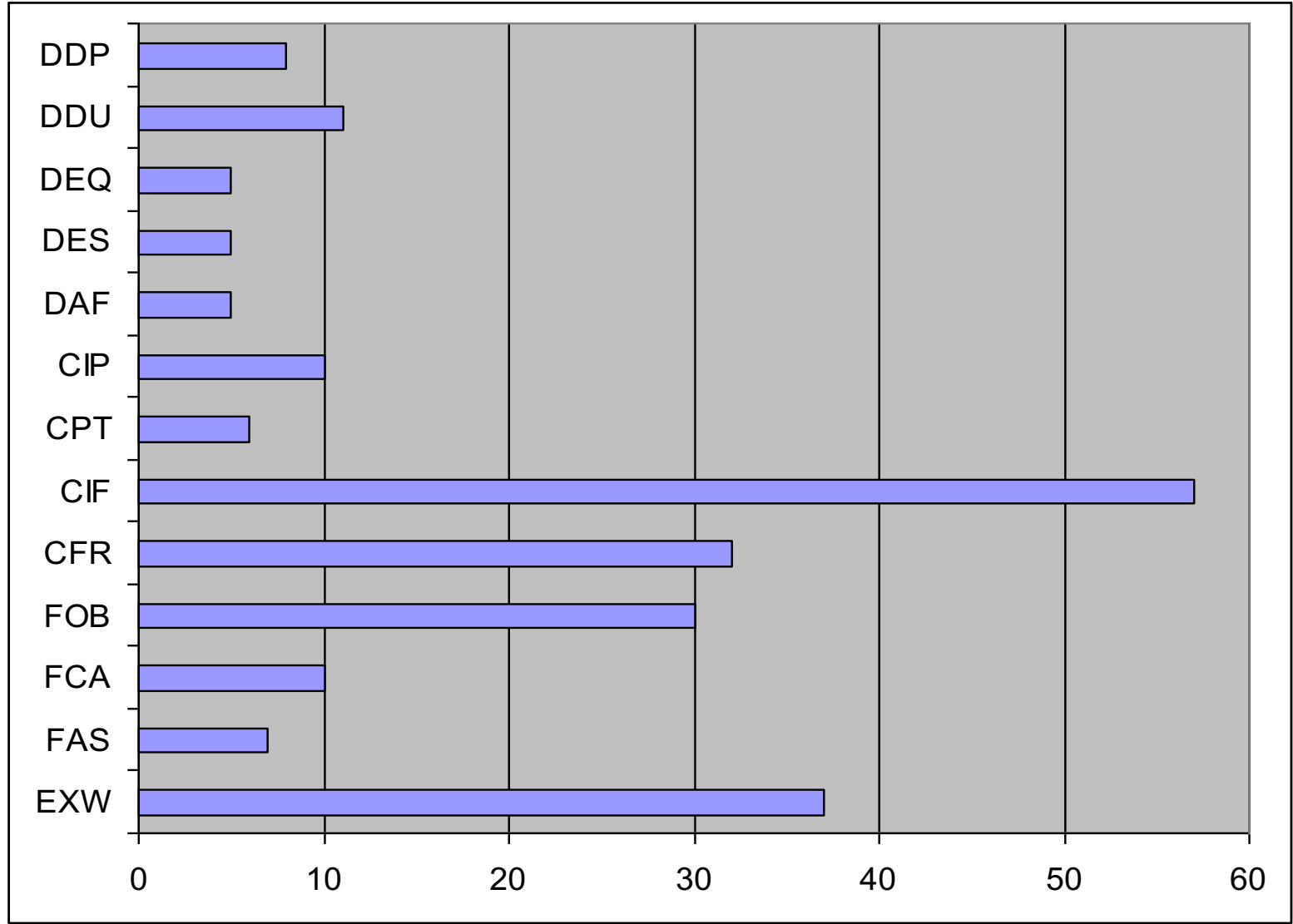

Figure 8: Incoterms preferences

It is clear that the term CIF is the most popular, followed by EXW, and then CFR and FOB. If the data is analysed on the basis of the Incoterms groups identified earlier, exporters appear to prefer to use of Group C terms, as shown in Figure 6. 


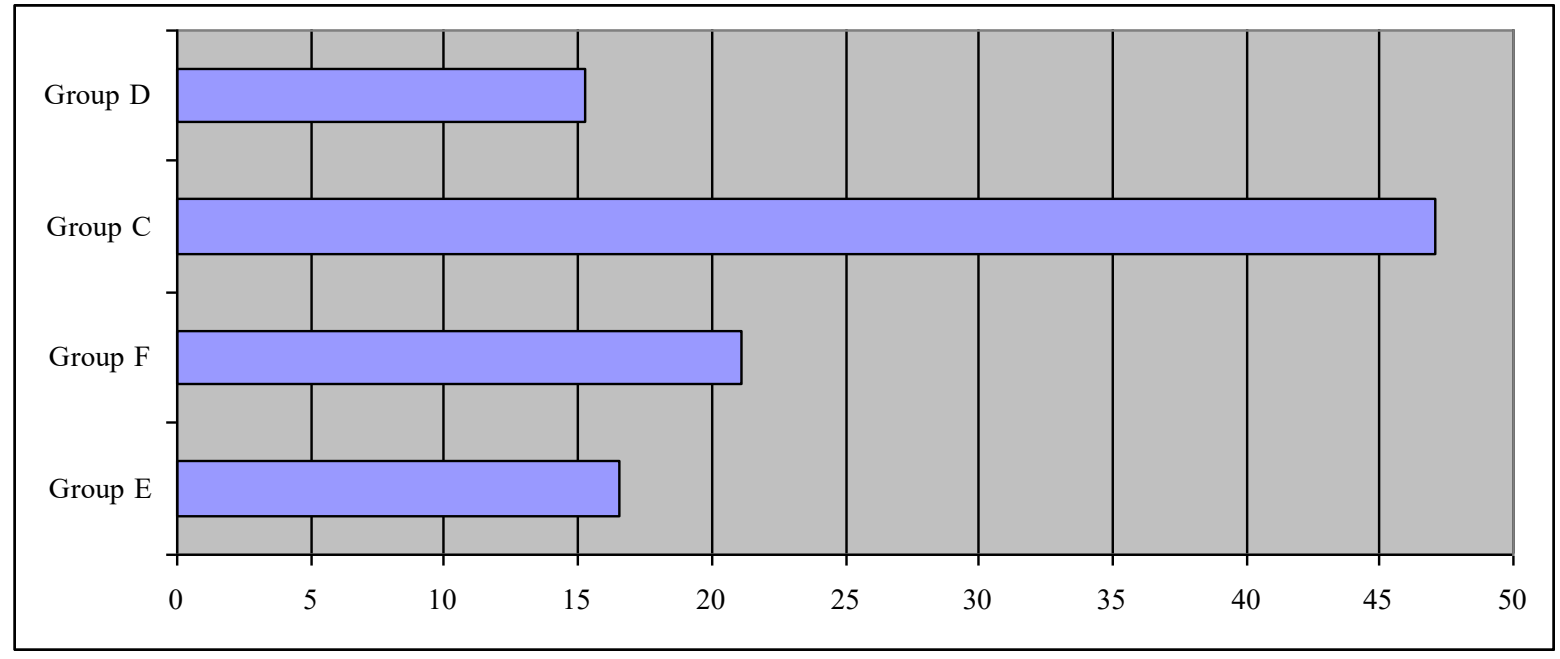

Figure 9: Incoterms Group preference

The most widely used mode of transport therefore links in with the above data and is shown below.

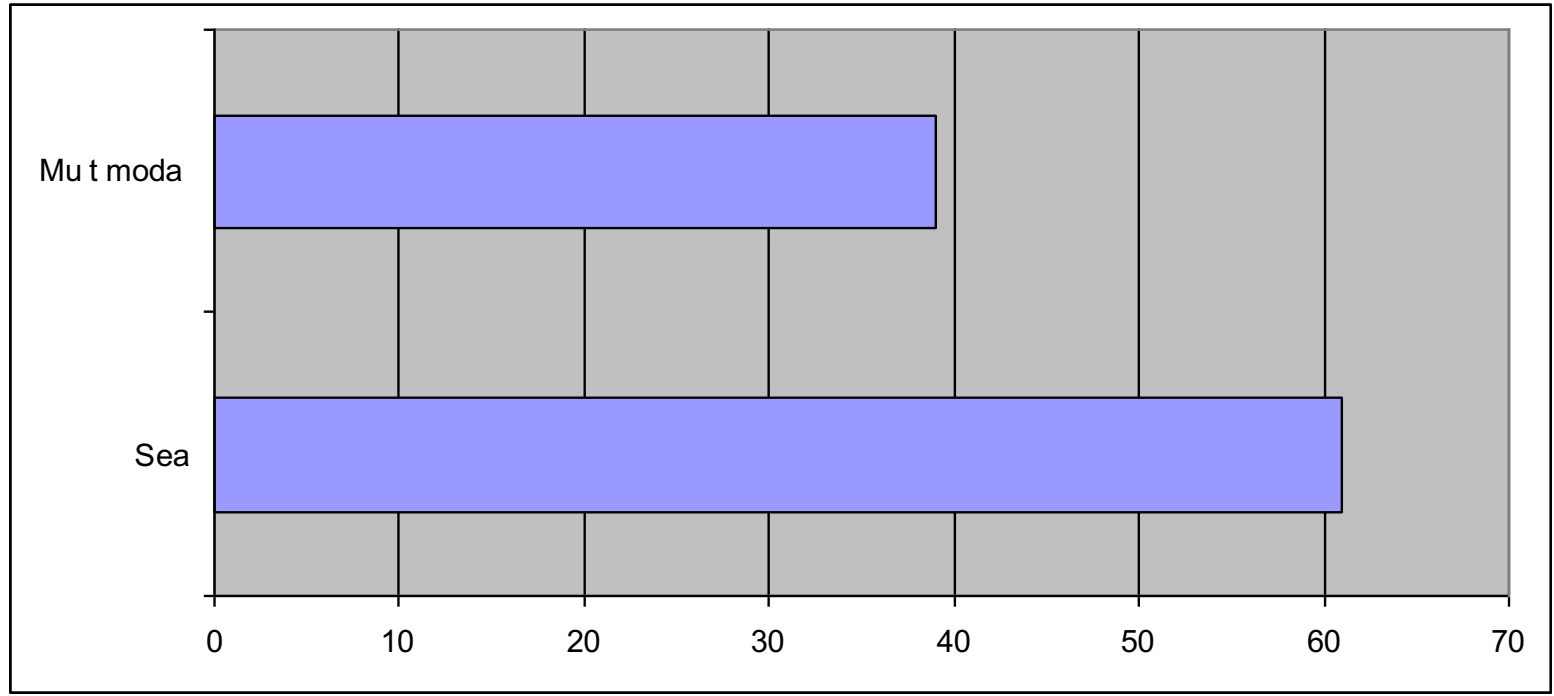

Figure 10: Mode of transport usage

\section{Linking Incoterms to Documentary Requirements}

In this section discussion will be limited to externally produced documents based on the Incoterms 2000 obligations. Internally produced documents are considered to be of a lesser risk category, because the exporter has control on their production and consequently control over their data content and manipulation. The same cannot be claimed for externally produced documents that may not be able to be changed, as doing so would be fraudulent. For example, changing the sailing date on a sea transport document would be an illegal act.

From Figure 5 it can be observed that CIF is the most popular term. This term has quite onerous documentary obligations for the exporter, demanding the provision of a transport document and evidence of insurance. It is significant to note that the responses shown in Figure 4 highlight that the transport and insurance documents are two of the most common problem areas. It is not possible to explain at this stage the reason for the popularity of this term and the associated area of discrepancies in the required documents.

EXW is shown as the second most preferred Incoterms option and this may be a good choice for exporters, given the minimal involvement required in a transaction, resulting in a equally minimal 
documentary requirement. There are no requirements for external documents in an EXW transaction. The presumption is that the exporter will be able to meet the documentary requirements of the $\mathrm{L} / \mathrm{C}$ because of his ability to control the production, and therefore, the data content of any document.

CFR and FOB are the next two most popular terms and, by comparison with the CIF term, these terms remove at least one source of discrepancies by not demanding the provision of an insurance document. Otherwise the documentary requirements remain the same.

The remainder of the terms in Figure 5 are more or less equally spread, and their documentary requirements are closely aligned with those of $\mathrm{FOB}$, insofar as a transport document or equivalent is to be provided to the buyer.

It is noteworthy that Group D terms, as shown in Figure 6 have proven to be the least popular group of terms and the explanation for this may be more the reluctance of exporters to become highly responsible for the placement of a consignment abroad, rather than a focus on documentation.

\section{Conclusion}

The $\mathrm{L} / \mathrm{C}$ is an important tool in international trade transactions and it is readily agreed to between buyers and sellers. For the exporter it provides a conditional guarantee of payment and a degree of financial certainty. However, there is a paradoxical situation that has developed with $\mathrm{L} / \mathrm{Cs}$, and that is the risk of non-payment through non-compliance.

The L/C mechanism is administered by the bank and payment will only follow the provision of compliant documents to the bank. The bank's role is merely to check the documents as an independent source of information without regard to any underlying contracts or other arrangements. Regardless of the relationship between the exporter and the buyer, the bank has an obligation to accept compliant documents on the one hand, and on the other refuse documents that fail to comply.

The documentary requirements of a L/C are influenced by the choice and inclusion of Incoterms into the contract of sale. The more onerous the terms are in relation to the burden of proof of delivery, the more paperwork will be demanded with a higher risk of discrepancies. It is logical to argue that as information requirements multiply the chances of errors likewise increase.

To ensure that exporters maximise their chances of documentary compliance, one approach may be to negotiate contracts with Incoterms that require the minimum of external documentation to be provided from exporter to buyer. The lesser the documents and data content the higher the chances of complying. Of course this argument is not without limitations. One such limitation may be the inability of the exporter to negotiate better Incoterms due to market considerations. However, this opportunity should be explored by the exporter if at all possible.

In conclusion, for exporters to maximise their documentary compliance under $\mathrm{L} / \mathrm{C}$ transaction the use of the EXW term is the preferred option, whilst the use of the CIF/CIP terms are to be resisted as these terms demand the highest level of documentation and data content, making it potentially more risky for the exporter to comply with the bank's requirements, thereby jeopardising payment.

\section{References}

AusIndustry 1996, Accessing export finance, FT Pitman Publishing, South Melbourne, Australia.

Bergami, R 2006, International trade: a practical introduction, $2^{\text {nd }}$ edn, Eruditions Publishing, Melbourne, Australia

D'Arcy, L, Murray, C \& Cleave, B 2000, Schmitthoff's Export Trade: The law and practice of international trade, Sweet and Maxwell, London, U.K.

Documentary Credit World 2003, 'Statistics: US Branches/Agencies of non-US banks', Documentary

Credit World, vol. Available at: $<$ http://www.iiblp.org/pdf/dcw/DCW\%20Oct\%202003.pdf $>$,

Accessed 16 August 2004, no. October, pp. 36 - 40. 
ICC Australian Council 1992, Newsletter and work in progress, Number 3, ICC Australia, Canberra, Australia.

ICC Thailand 2002, Examination of documents waiver of discrepancies and notice under UCP500, viewed 1 June $2004<$ http://www.iccthailand.or.th/article2.asp?id=9>.

International Chamber of Commerce 1993, Uniform Customs and Practice for Documentary Credits, ICC Publishing, SA, Paris.

---- 1999, Incoterms 2000, ICC Publishing, S.A., Paris, France.

---- 2004, Document 470/TA.564 rev, International Chamber of Commerce, Paris.

Mann, RJ 2000, 'The role of letters of credit in payment transactions', Michigan Law Review, vol. 98, no. 8, pp. pp. 2494-547.

Ramberg, J 1999, ICC Guide to Incoterms, ICC Publishing, S.A., Paris, France.

SITPRO Ltd. 2003, Report on the use of export letters of credit 2001/2002, SITPRO Ltd.,, London.

Technical Officers of Global International Trade \& Business Finance 2000, Finance of International Trade, $9^{\text {th }}$ edn, Natinal Australia Bank, Melbourne, Australia.

United States International Trade Commission 2004, U.S. Trade by geographic regions, United States International Trade Commission, viewed 16 August 2004, $<$ http://dataweb.usitc.gov/scripts/Regions.asp $>$. 